\title{
New trends in regulatory rules and surveillance of antimicrobial resistance in bacteria of animal origin
}

\author{
Jean-Louis MARTEL ${ }^{\mathrm{a} *}$, Florence TARDY $^{\mathrm{a}}$, \\ Pascal SANDERS ${ }^{\mathrm{b}}$, Jacques BoISSEAU ${ }^{\mathrm{c}}$
}

a Agence Française de Sécurité Sanitaire des Aliments, Site de Lyon, Laboratoire d'Études et de Recherches en Pathologie Bovine et Hygiène des Viandes,

31 avenue Tony Garnier, 69364 Lyon Cedex 07, France

b Agence Française de Sécurité Sanitaire des Aliments, Site de Fougères, Laboratoire d'Études et de Recherches sur les Médicaments Vétérinaires et les Désinfectants, La Haute Marche, Javené, 35302 Fougères, France

${ }^{c}$ Agence Nationale du Médicament Vétérinaire, BP 90203, 35302 Fougères, France

(Received 6 February 2001; accepted 30 March 2001)

\begin{abstract}
Since the introduction in the 1940s of antibiotics as drugs against bacterial infections in human and then veterinary medicine, two major events have caused a shift in the antibiotherapy era: (1) the emergence of resistant bacteria and (2) the awareness of the limits of new drug development. It rapidly became urgent to set up measures in order to evaluate the importance of resistant bacteria and their origin as well as to limit the dissemination of resistant vectors (bacteria and bacterial genes). This led to the establishment of guidelines and regulatory rules necessary for risk assessment and clearly dependent upon monitoring and research organisations. At a veterinary level, the possible dissemination of multiresistant bacteria from animals to humans, through feeding, urged various national European and international institutions to give general recommendations to monitor and contain the emergence and diffusion of resistant strains. This paper gives an overview of the evolution of regulatory rules and monitoring systems dealing with multiresistant bacteria.
\end{abstract}

epidemiology / surveillance / resistance to antibiotics / regulatory rules

Résumé - Nouvelles tendances concernant la législation et la surveillance de la résistance aux antibiotiques chez les bactéries d'origine animale. Depuis l'introduction, dans les années 1940, des antibiotiques comme médicaments antibactériens en médecine humaine puis vétérinaire, deux événements majeurs ont marqué l'ère de l'antibiothérapie : l'émergence de bactéries résistantes et la prise de conscience des possibilités limitées de développement de nouvelles molécules. Il est apparu rapidement urgent d'établir des mesures pour évaluer l'importance des résistances et leur origine ainsi que pour limiter la dissémination des vecteurs de résistance (bactéries et/ou gènes bactériens). Ceci a

* Correspondence and reprints

Tel.: (33) 4787265 43; fax: (33) 4786191 45; e-mail: jl.martel@lyon.afssa.fr 
conduit à l'élaboration de guides et réglementations nécessaires à la gestion du risque et dépendant des systèmes de surveillance et de recherche. Au niveau vétérinaire, la possible dissémination de souches multirésistantes des animaux vers l'homme à travers l'alimentation a conduit différentes instances nationales, européennes et mondiales à émettre des recommandations générales pour surveiller et limiter l'émergence et la diffusion de ces résistances. Ce texte présente un état des lieux de l'évolution des textes réglementaires et des systèmes de surveillance des bactéries multirésistantes aux antibiotiques.

épidémiologie / surveillance / antibiorésistance / réglementation

\section{Table of contents}

1. Introduction.

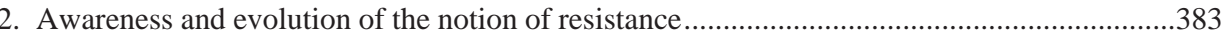

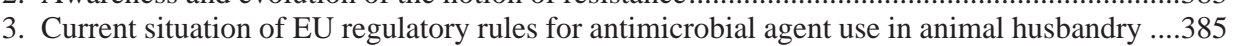

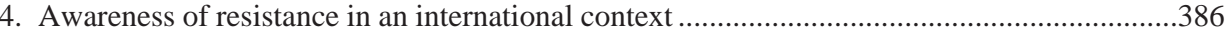

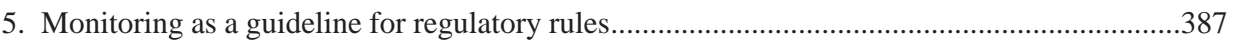

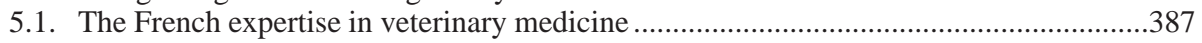

5.2. The present situation and the need for a new strategy in the European Union .................389

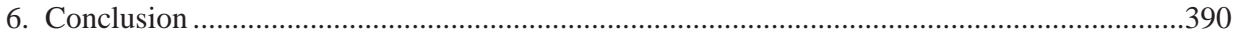

\section{INTRODUCTION}

Antimicrobial agents represent one of the major medical advances of the 20th century with the introduction into human medicine of sulphanilamide, in 1936, rapidly followed by benzylpenicillin (1943), streptomycin (1944), chloramphenicol (1947) and chlortetracycline (1948) [14]. However, since the introduction of antimicrobial agents into clinical use, the therapeutic efficacy of the currently available drugs has been increasingly compromised by the development of bacterial resistance. Awareness of the problems raised by antibiotic resistance started long ago and was anticipated by Sir Alexander Fleming in the 1940s when penicillin became available for human medicine. Two main strategies exist to combat the emergence of bacterial resistance. One option attempts to identify and develop new antibacterial agents. Historically, this was achieved through (i) the use of naturally produced antibiotic agents (such as penicillin G); (ii) the development of semisyn- thetic molecules whose structure is based on an active antimicrobial core protected by artificially added chemical groups (such as penicillin A) and (iii) the design of fully synthetic molecules (such as fluoroquinolones). Alternatively, another option is to devise strategies in order to prevent the emergence of resistant bacteria and to limit their spread once they have appeared. The importance of implementing such policies is increasing since the number of new therapeutic options are now well limited. An extensive understanding of the mechanisms of drug resistance and its epidemiology is required if effective policies are to be devised. In this context, it is also important to understand the role animals play in providing potential reservoirs of drug resistance. The present paper reviews some relevant aspects of scientific progress in microbiology, epidemiology and clinical studies for the actual concept of antimicrobial resistance, gradually leading to the actual state of regulatory rules and their future evolution. As a specific measure, the 
surveillance of resistance, involving a lot of subsequent research, is essential and will be given special attention.

\section{AWARENESS AND EVOLUTION OF THE NOTION OF RESISTANCE}

The development of antimicrobial resistant bacteria is a hazard associated with drug use in both human and veterinary medicine. Indeed as early as the 1950 s, the use of antibiotics as therapeutic agents was not reserved for human beings but was also developed for both farm animals and domestic pets to treat identified bacterial infections and to prevent any bacterial infection in animals at risk. This new field of antibiotic use has contributed to improve animal health and welfare and to markedly increase the productivity of livestock.

In 1946, residual antibiotics in the mycelial mass released after the fermentation process and used as a raw material for the animal feed industry was found to have a growth enhancement effect. The use of certain Antimicrobials as Growth Promoters (AGP) as a feed additive became widespread in Europe as well as in the US, Japan and elsewhere. For this particular use as AGP, at so-called sub-therapeutic or infra-therapeutic level, it was soon decided that antibiotics could be delivered without veterinary prescription. An important point to note is that AGP are used in animal feeds at low levels, below Minimum Inhibitory Concentrations (MIC), thus no therapeutic effects are to be expected.

The debate about the extent to which the use of antibiotics in animal husbandry - as AGP and/or therapeutics - might contribute to the problems of bacterial resistance to antimicrobials used in human medicine, has been going on for more than 30 years particularly in Europe (see the Swann committee [26]) and is still a burning and controversial issue [4, 27, 28].
Whatever the outcome of this debate is, what is really clear is that the widespread use of antibiotics rapidly leads to the selection of resistant bacteria. Indeed, even if resistance to antimicrobials has always existed as a "natural" phenotypic bacterial character, selection pressure in the presence of antimicrobial drugs greatly contributes to the rapid acquisition of resistance through mutations and exchanges of genetic determinants (plasmid, transposon...). Therapeutic failure in human and veterinary medicines due to the lack of effective antibiotics became a real threat very soon after the first introduction of antibiotics. In 1955, numerous isolates of the specifically human pathogen Shigella dysenteriae resistant to streptomycin, chloramphenicol, tetracycline and sulfamides were detected in Japan. Since this multiresistant phenotype could not be explained by successive mutations, the possible transfer of genetic resistance determinants - that were later on identified as plasmids - was soon suggested (for a review see [1]). In recent years, there has been substantial progress in our knowledge of bacterial resistance to antibiotics. Studies on the biochemical and genetic mechanisms of resistance of strains representative of the various phenotypes detected have led to elucidation of cross-resistance, not to be confused with multiresistance. The goal of the combined molecular and therapeutic interpretation of antimicrobial susceptibility tests is to provide an improved logical basis for decision-making in antibiotic therapy by taking into account the recent progress in the understanding of bacterial resistance. Finally, biochemical resistance is due to mutations or acquisition of exogenous DNA and refers to the parental strain considered susceptible. It does not always correlate with clinical resistance. Currently, a consensual definition of resistance, in the field of public health, has been proposed by the World Health Organisation (WHO) after an electronic consultation of various experts: antimicrobial resistance is "the ability of a micro-organism to continue to multiply or 
persist in the presence of therapeutic levels of an antimicrobial agent" [30].

Awareness of the rising public health concerns due to the spread of resistance soon arose in human and veterinary medicine. In the UK, during the 1960 s, the increase of resistant strains among Salmonella isolated from young calves intended for human consumption urged the creation in the UK of the Joint Committee on the Use of antibiotics in Animal husbandry and Veterinary medicine. The Joint Committee concluded that the administration of antibiotics to farm livestock, particularly at sub-therapeutic levels could pose hazards to human and animal health [26]. As a result, the use of penicillin and tetracycline as AGP was banned by the EU. These two antibiotics, together with sulphonamides, became available for animals only on veterinary prescription and for the treatment of infections.

From then on, the EU has been in charge of establishing a rational use of antibiotics as therapeutic agents and as growth promoters. As early as 1978, the WHO set up an expert committee in charge of defining rules for networks able to monitor resistance among enterobacteria, including enterobacteria of animal origin, taking into account their possible transfer to humans [29]. The international collaborative study launched by Ericsson and Sherris in 1971 constituted a key step for the setting up of monitoring networks since it assessed the various methodologies used for antibiotic activity testing [15]. Monitoring resistance to antibiotics is indeed greatly dependent upon the harmonisation and standardisation of methodologies. Nevertheless, from the 1970s onwards, reports about multiresistant bacteria continued to multiply. More recently certain bacteria resistant to all clinically available antibiotics were also described [25].

In 1995, with the entry of Sweden and Finland into the EU a new debate arose. These two countries both obtained a derogation not to use antibiotics as AGP. Swe- den, for instance, had decided to prohibit AGP since 1986. This ban was immediately followed by an increase of bacterial infections which resulted in an increased therapeutic use of antibiotics. These dramatic consequences brought about radical changes in animal husbandry systems and feed formulation and, in the end, these changes allowed to balance the undesirable effects of the ban [31]: a post-antimicrobial era began and the debate on the validity of AGP use intensified.

Over the last five years, many scientific meetings have been organised in Europe by international or European bodies and national organisations or regulatory bodies. For instance, the WHO organised two meetings: one in October 1997 on the "medical impact of the use of antibiotics in food animals" and one in June 1998 on "the use of fluoroquinolones in food animals and potential impact on human health" (WHO recent report summaries can be found at http://www.who.int/emc/diseases/zoo/antimi crobial.html). Under a Scandinavian initiative, in 1998, a meeting was held in Copenhagen where participants recognised that the major contributor to antibiotic resistance in human pathogens was clinical use in human medicine but that the overall reduction of antibiotic resistance required the pursuit of common principles in both human and veterinary medicine. A European strategy against the microbial threat was defined [12]. The council of Agriculture Ministers for instance decided to ban some antibiotics used at sub-therapeutic levels as growth promoters [11]. The last four molecules still authorised as AGP today in Europe (namely: avilamycin, flavophospholipol, monensim sodium and salinomycin sodium) have no structural relation with antimicrobial drugs used in human and veterinary medicine.

The European Council also recognised that the risk of development and spread of antibiotic-resistant microorganisms requires a co-ordinated strategy at Community and international level. The major recommendations were to develop risk analysis to 
evaluate new drugs before authorisation, to collect and analyse information on antibiotic use, to define antibiotic policy and develop a surveillance programme of antibiotic resistance in all the reservoirs of bacteria (humans, animals, flora, environment) where antibiotic resistance genes may emerge and be transmitted. In September 1999, a symposium held in the Swedish town of Falkenberg emphasised the issue of animal-human transfer (see for instance [4]). Another major impact of all these meetings was to underline the importance of monitoring the effects of any political interventions and strategies in terms of the control and containment of antimicrobial resistance.

\section{CURRENT SITUATION \\ OF EU REGULATORY RULES \\ FOR ANTIMICROBIAL AGENT USE IN ANIMAL HUSBANDRY}

In the EU, the authorisation of all veterinary medicines including antibiotic products for animal therapy is part of a harmonised procedure as established in Council Directives 81/851/EEC [7] and 81/852/EEC [8]. A marketing authorisation is required before any product can be sold or supplied. The authorisation of the product is granted after a thorough assessment on the criteria of quality, safety and efficacy. Three main procedures for granting marketing authorisations have been used since 1998: the centralised and the decentralised systems for authorisation in the EU as well as national systems for products marketed in one country only. The three procedures operate on the basis of the EU legislation and guidelines. The pre-authorisation tests for veterinary medicinal products are defined in Volume VII of the rules governing Medicinal Products in the EU [16]. Susceptibility patterns of target bacteria are requested, and the extent to which resistance can develop as well as the possibility for the normal flora to acquire resistance are topics to be covered in the safety and efficacy files. A maximum residue limit for new and existing active substances used in veterinary medicinal products for food-producing animals has to be established under Council Regulation (EEC) 2377/90 [10]. Antimicrobials used as veterinary drugs are subject to veterinary prescription and must be administered to animals under the supervision of a veterinary surgeon. The summary of product characteristics contains the information necessary for appropriate use by the veterinary surgeons. For new compounds, and if this is justified by the safety evaluation, the sponsor could have to implement a specific surveillance programme after the granting of the marketing authorisation to assess the impact of the use of an antimicrobial agent on the selection of antimicrobial-resistant bacteria in food producing animals. Sometimes, the surveillance programme should evaluate not only the antimicrobial resistance in target animal pathogens but also in foodborne pathogens and/or indicator bacteria.

Growth promoters have been authorised in the EU since the 1970s under Council Directive 70/524/EEC [6] that was followed by numerous amendments and derogations. Authorisation depends on the data submitted which must meet the requirements of Council Directive 87/153/EEC (as amended) [9] which addresses the question of resistance through information collected on MICs, cross-resistance to therapeutic antibiotics and effects on the gut microflora of animals, including the shedding of pathogenic microorganisms. Products used for the control of coccidiosis in animals can be classified as growth promoters or veterinary drugs and may also have an antibiotic activity. The surveillance of animal bacteria resistant to these antimicrobial agents has been developed in a few countries during the last decade. The data collected through these surveillance programmes and through specific epidemiological studies in animals, food products of animal origin, and people in the animal environment, contribute towards the re-evaluation of the safety of 
different compounds. As a consequence, in 1998, in accordance with the precautionary principle, the Council of Agriculture Ministers also decided to ban certain antibiotics used at sub-therapeutic levels as growth promoters [11]: avoparcin (1997), ardacin (1998), carbadox and olaquindox (1999), and bacitracine, spiramycin, tylosin and virginiamycin (1999). In April 2000, only four antibiotics were authorised to be used at sub-therapeutic levels as growth promoters: avilamycin (E 717), flavophospholipol (E 712) and two ionophores with a low antibiotic activity but with a coccidiostatic effect: monensin sodium (E 714) and salinomycin sodium (E 716).

\section{AWARENESS OF RESISTANCE IN AN INTERNATIONAL CONTEXT}

At an international level, it is of particular importance that the "Office International des Épizooties" (OIE) and Codex Alimentarius, two international organisations recognised as reference bodies for the Sanitary and Phytosanitary Agreement of the World Trade Organisation, get involved in this public health problematic. According to their terms of reference, they have to release standards likely to guarantee the sanitary status of food-producing animals and the hygienic quality of animal-derived food in order to efficiently protect public health, which covers both human and animal health. In addition, they have to favour, among others through these standards, the international trade of food-producing animals and animal-derived products. Therefore, their actions will necessarily influence trends in European legislation and surveillance regarding the antimicrobial resistance of bacteria from animals.

The technical guidelines prepared in November 2000 by the OIE international expert group will certainly represent a milestone among all the efforts made to keep the spread of animal resistant bacteria under control. The key issue is certainly the description of a risk analysis approach applied to this problem of public health. Beyond the general recommendations about separation of responsibilities in risk assessment and risk management, transparency of these two procedures, risk assessment to be based on science and to be carried out before any regulatory measure be taken, valuable alternative options have been proposed about risk assessment which may be, on a case by case basis, qualitative, quantitative or semiquantitative. All the criteria to be taken into consideration for conducting these risk assessments have been listed.

The guideline on the prudent use of antimicrobials in veterinary medicine, beyond the classical recommendations targeted at the different concerned stakeholders, insists on the specific responsibilities of the regulatory authorities in charge of granting marketing approvals for veterinary medicinal products. It is important to remind that, based on the outcome of the evaluation of the quality, safety and efficacy of these products, marketing approvals provide - through the summaries of product characteristics - all the information required for a prudent use of these products. It is therefore important that all the regulatory authorities operate in order to maximise the area covered by the marketing authorisations and to minimise the out-of-label use of veterinary medicinal products. The implementation of such a code of prudent use is of particular importance in developing countries, which do not have the resources necessary for carrying out the surveillance of resistant bacteria. This code will urge these countries to develop an appropriate strategy, to strengthen the registration of the veterinary medicinal products and the technical control of their distribution.

The prudent use of antimicrobials will lead, as should also be the case in human medicine, to a reduction in the amounts of these products which are currently used in veterinary medicine. In all the countries, the survey of the amounts of each type of 
antimicrobial used with specific information on the targeted animals, the type of use (therapeutic or animal feed additive), and the route of administration (parenteral or oral) will provide valuable information that must be linked with the result of the antimicrobial resistance surveillance programmes.

The technical guideline regarding the surveillance of animal resistant bacteria and the antimicrobial susceptibility testing methodologies highlights the need to use harmonised methods in laboratories working under the internal quality assurance scheme, in order to provide quantitative data which can be compared and consolidated. Data derived from these surveillance programmes have to be taken into consideration for amending or optimising, if necessary, the risk assessments already made, the regulatory measures taken for containing antimicrobial resistance, the conditions of antimicrobial use in veterinary medicine as stated by the marketing approvals granted.

It is also noteworthy that Codex Alimentarius has decided to get involved in this issue of public health and has asked two committees, Codex Committee on Food Hygiene (CCFH) and Codex Committee on Residues of Veterinary Drugs in Food (CCRVDF), to forward proposals in view of their possible involvement in this domain. The CCFH, made up of representatives responsible for food hygiene in various countries, may consider general hygiene measures in order to reduce microbial contamination in food, covering both sensitive and resistant animal bacteria. The CCRVDF, made up of persons responsible for the management of veterinary drugs, specifically with regard to the protection of public health, appears to be the appropriate committee for proposing specific measures for a rational (that is to say likely to strengthen the containment of resistant animal bacteria resulting from the use of antimicrobials in animal husbandry) use of veterinary medicinal products.

\section{MONITORING AS A GUIDELINE FOR REGULATORY RULES}

\subsection{The French expertise in veterinary medicine}

Surveillance of antimicrobial resistance in bacteria of animal origin in France is for instance carried out by the French Agency for Food Safety (Agence Française de Sécurité Sanitaire des Aliments, AFSSA) through two types of networks, either monocentric or multicentric [22]. The first type (Salmonella network) is based on gathering non-human zoonotic Salmonella isolates in one centre (AFSSA-Paris) where these strains are systematically tested for their antimicrobial susceptibility. The other type of networks, managed by AFSSA-Lyon (Réseau d'ÉpidémioSurveillance de l'Antibiorésistance des principales bactéries pathogènes des BOvins, RESABO), deals with bovine pathogenic isolates and is multicentric, that is to say it is based on directly collecting antibiotic susceptibility data from the local public veterinary diagnostic laboratories that routinely perform isolation, identification of the bacterial species and of antibiotic susceptibility. These laboratories are provided, within the scope of the RESABO, with forms containing entries for the following computerised data: when and where the bacteria were isolated, in which clinical conditions, identification of the bacteria, results of the antibiotic resistance testing. Species selected for this epidemiological monitoring of resistance include Escherichia coli and Salmonella for digestive infections, Pasteurella multocida and Mannheimia haemolytica for infections of the respiratory track and Staphylococcus spp. and Streptococcus spp. for mammary infections. As a member of ONERBA (Observatoire National de l'Épidémiologie de la Résistance Bactérienne aux Antibiotiques), RESABO follows the recommendations of this national organisation, ensuring data obtained in veterinary medicine are comparable with data from human medicine. In 
2001, surveillance focused on bovine bacterial pathogens through RESABO will be extended to bacterial pathogens found in avian and porcine production. The principles for monitoring elaborated through RESABO are adapted for the other two animal productions strongly marked by industrialisation. The new unique network named RESAPATH (Réseau d'ÉpidémioSurveillance de l'Antibiorésistance des principales bactéries PATHogènes vétérinaires) will be managed through the collaboration of a laboratory in charge of bovine diseases (AFSSA-Lyon) and a laboratory in charge of avian and porcine diseases (AFSSA-Ploufragan). This type of multicentric network requires considerable standardisation of the methods used in each partner laboratory. The highly standardised disc diffusion method, the most widely used antimicrobial susceptibility test in both human and veterinary microbiology, was chosen as the network methodology. Measures of the antimicrobial resistance are performed either by automated systems or by manual reading of the inhibitory diameters of antibiotic discs. Results are analysed as numerical data and interpreted according to the "Comité de l'Antibiogramme de la Société Française de Microbiologie" [5] (Resistant, Intermediate, Susceptible) or, for certain animal pathogens, according to the NCCLS subcommittee on Veterinary Antimicrobial Susceptibility Testing [24].

All the results of bacteriological analyses, together with the results of antimicrobial susceptibility testing, are stored as numeric data into a computer database, taking into account, for each isolated pathogen, the localisation and age of the diseased animal, the type of disease (enteric, septicaemic, respiratory, mastitis...), and the nature of the samples. These data allow statistical analyses of resistance evolution on the French territory as a function of strain pathogenicity and/or of the "ecological" origin of the isolate.

For instance, from the Salmonella network, a general overview of the National situation regarding Salmonella spread and resistance can be provided. Although the main Salmonella "reservoir" is the animal sector, monitoring also covers the field of animal food processing and food products and general environments including sea and river waters, foodstuffs, vegetables... From RESABO, the evolution of resistance of the main pathogens can be followed over years and trends linking multiresistance and pathogenicity can be assessed. For instance it was inferred that among $E$. coli isolated from newborn calf diarrhoea K99 positive strains are more resistant than K99 negative strains.

In addition to giving trends in the evolution of antimicrobial resistance, the epidemiological data generated by such a network give rise to research projects for the identification of molecular mechanisms underlying resistance. They also lead to the development of efficient collaboration between veterinary surgeons and research laboratories, a collaboration which improves both the quality of routine antibiotic testing and the understanding of the molecular mechanisms underlying resistance. As an example of collaborative study, a large surveillance was organised to measure the evolution of resistance to quinolones in Salmonella. The frequency of isolation of Salmonella strains resistant to nalidixic acid and with a reduced susceptibility to enrofloxacin and to ciprofloxacin was increasing in the surveillance networks. In studies undertaken at the "Institut National de la Recherche Agronomique" (INRA), spontaneous mutants of Salmonella Typhimurium resistant to ciprofloxacin were selected in in vitro and in vivo experimental conditions [20]. Mutants experimentally selected from chickens could not reach the same levels of resistance to ciprofloxacin as the in vitro-selected mutants. The highly fluoroquinolone-resistant mutants exhibited drastically reduced growth on solid media compared to the field strains. Studies of mechanisms of resistance to quinolones in the field strains and in in vitro and in vivo- 
selected mutants revealed the presence of mutations limited to gyrA. In all these experimental mutants, an overproduction of the efflux system AcrAB was demonstrated and there was a good correlation between the levels of resistance and the levels of production of the efflux system AcrAB [20]. These results suggest that the mechanisms leading to a high level of resistance to fluoroquinolones could be deleterious and could therefore be counterselected under in vivo conditions. Work is ongoing on this aspect.

\subsection{The present situation and the need for a new strategy in the European Union}

However, as largely illustrated by the EU-funded symposium held in Paris (concerted action FAIR5-CT97-3654) in November 1999, some other national monitoring programs for resistance in bacteria of animal origin exist in Europe (for a review see [32]). For instance, the Danmap network in Denmark also includes data about the consumption of antibiotics as AGP, veterinary and human drugs [2]. The perfect network should be able to set up comparisons between data from both animal and human medicines.

However, it appears that there are many different monitoring programmes and monitoring methodologies in European countries [3, 21]. Approaches, objectives and methods are different. The European overview presented in the special issue of the International Journal of Antimicrobial Agents underlined the urge to define a common European strategy for monitoring [23].

Then, the objectives of the surveillance are today multiple and at least partly modify the existing national programmes [32]. These new objectives are included in a global programme against antimicrobial resistance [17] and should be reached through the organisation of European networks following the general principles of decision 2119/98/EC [13]. Indeed, one of the major objectives of the former surveillance network of pathogenic bacteria was to give information about antibiotic resistance levels in order to help veterinary surgeons and physicians determine the first empirical treatment of individual cases. In the new surveillance system oriented towards epidemiology, programs are set up either to detect the emergence of new resistance mechanisms (they then constitute an early warning system), either to follow the clonal spread of one particular phenotype of resistant bacteria (ex: Methicillin-resistant Staphylococcus aureus, Vancomycin-Resistant Enterococci, pentaresistant Salmonella Typhimurium). These "new" monitoring systems must (i) help establish sanitary measures in hospitals, communities or herds with respect to the resistant bacteria concerned; (ii) assess the long-term trends in the general evolution of resistant bacteria. These trends can be affected by empirical therapy, by local antibiotic policies proposed to minimise further development of resistance, or by legislation (antibiotic as AGP, restriction availability...). In the veterinary field, different kinds of structures like diagnostic laboratory networks (such as the RESABO in France), local surveillance and monitoring project centred on clinicians or production organisations, national randomised sampling plans could be used and combined to attain this objective.

A concerted action launched in 1998 has recently reviewed the existing national programmes in Europe and proposed new trends in the surveillance of antibiotic surveillance in bacteria of animal origin (for reviews see [3, 23]). Three levels of surveillance were proposed after discussion: (i) the veterinary pathogens which are considered as bacteria under greater selection pressure; (ii) the bacteria in the intestinal flora, which are the major reservoir of bacteria and under the indirect pressure of antibiotics administered by oral route or excreted in the intestinal lumen and (iii) the zoonotic bacteria which can be transmitted to humans by direct contact or via oral route with 
contaminated food. Several technical recommendations of this group should orient in the future the organisation of antibiotic resistance surveillance in the veterinary field in Europe. Many of these recommendations are also commonly shared by the WHO, in its global principles for the containment of antimicrobial resistance in animals intended for food, given in a report of a WHO consultation in Geneva [30] and by the expert groups created on this subject by OIE in 2000 (conclusions of these groups will be delivered in a meeting organized in 2001).

The data collected through networks have to be analysed and interpreted at different levels (local, regional, national, continental, world) to optimise antibiotic use by way of local guidelines, improvement of summary of product characteristics, national or international antibiotic policies, definition of an international threshold, etc. An important field of research will be to understand the relationship between drug consumption and antimicrobial resistance and to develop the tools allowing an adapted response as a function of the epidemiological situation. At an international level, one of the first steps to that end was realised by the Food and Drug Administration (FDA) in an approach for establishing thresholds in association with the use of antimicrobial drugs in food producing animals [18]. For example, FDA recently proposed to withdraw approval of the New Animal Drug Application (NADA) for use of the fluoroquinolone enrofloxacin in poultry [19]. This action is based on FDA's findings that enrofloxacin use in poultry causes development of fluoroquinolones-resistant campylobacters, afterwards transmitted to human. Post-marketing regulatory amendments could become more and more frequent as precautionary measures.

\section{CONCLUSION}

In general, since the 1940 s, antibiotics have been used for animal health and for human medicine in the same context, that is to say treatment and prophylaxis of bacterial diseases. Most of the time, the types of molecules used are also similar, although veterinary products often tend to lag behind antibiotics available for humans.

In most developed countries, all medicines must fulfil strict criteria of safety, quality and efficacy. A major question must be "is it safe for the patient?" regardless of whether that patient is a human or an animal. In addition, for veterinary drugs, safety criteria must also apply for consumers of animal products. To ensure that these criteria are met, countries have introduced elaborate and often complex regulatory systems.

Beyond their use in veterinary medicine and prior to 1950 , some antibiotics were found to have a growth promoting effect when they are used at low levels, below MIC. Since then, the use of antibiotic growth promotors has become widespread particularly in rearing intensive units of birds, pigs and young calves. In the EU they are not regarded as veterinary medicines at all, but as zootechnical feed additives, and they are regulated independently under a separate directive.

The emergence of antimicrobial resistance was contemporaneous with the intensive use of antibiotics and is still, at the beginning of the 3rd millennium, a major threat to the effectiveness of human and animal health care systems. As the importance of selective pressure became apparent, recommendations for the prudent use of antibiotics were made in order to contain antimicrobial resistance.

However, selective pressure is not the unique cause of emergence of antimicrobial resistant isolates of medical and veterinary pathogens. Antimicrobial resistance is a multifactorial problem and requires a multifaceted solution. Antimicrobial resistance is also a matter of food safety and we cannot only speculate on the spread of resistance from animals to man without any data nor on 
the prevalence of resistance in the normal flora of healthy animals intended for food.

The development of a permanent antibiotic resistance surveillance program, including research programmes if necessary, will serve as a base for the global approach necessary to contain this problem.

The first step in the field of animal health and food safety for the beginning of the third millennium in the European Union would be to create a European surveillance network. The second step would be to exchange experience and ideas between the experts of different countries in the world to locally determine the best way to contain the problem of antibiotic resistance globally. The collection of new data obtained by different teams in different countries with harmonised laboratory tools will enable us to improve our knowledge of the problem thus leading to a better and rational use of antibiotics.

\section{REFERENCES}

[1] Anderson E.S., The ecology of transferable drug resistance in the enterobacteria, Annu. Rev. Microbiol. 22 (1968) 131-180.

[2] Anonymous, DANMAP 99, Consumption of antimicrobial agents and occurrence of antimicrobial resistance in bacteria from food and humans in Denmark, ISSN1600-2032. The report is also available on http://www.svs.dk/uk/Organization/Frm_org.htm.

[3] Caprioli A., Busani L., Martel J.-L., Helmuth R., Monitoring of antibiotic resistance in bacteria of animal origin: epidemiological and microbiological methodologies, Int. J. Antimicrob. Agents 14 (2000) 295-301.

[4] Chaslus-Dancla E., Lafont J.-P., Martel J.L., Spread of resistance from food animals to man: the French experience, Proceedings of the Symposium on Antibiotic Resistance with Emphasis on Animal-Human Transfer hold in Falkenberg, Sweden, 13-14 September 1999, Acta Vet. Scand. Suppl. 93 (2000) 53-61.

[5] Comité de l'Antibiogramme de la Société Française de Microbiologie (CASFM), Communiqué 2000-2001, pp. 1-46. On http:// www.sfm.asso.fr/Wfr.html (http://www.sfm. asso.fr/Sect4/com2001.pdf).
[6] Council Directive 70/524/EEC of 23 November 1970 concerning additives in feeding-stuffs, Official Journal L270, 14/12/1970, pp. 1-17.

[7] Council Directive $81 / 851 /$ EEC of 28 September 1981 on the approximation of the laws of the Member states relating to veterinary medicinal products, Official Journal L317, 06/11/1981.

[8] Council Directive 81/852/EEC of 28 September 1981 on the approximation of the laws of the Member states relating to analytical, pharmacotoxicological and clinical standards and protocols in respect of the testing of veterinary medicinal products, Official Journal L317 of 6 Nov 1981, Amended by Council Directive 87/20/EEC, 92/18/EEC and 93/40/EEC.

[9] Council Directive $87 / 153 /$ EEC of 16 February 1987 fixing guidelines for the assessment of additives in animal nutrition, Official Journal L064, 7/3/87, 19-28. amended by Commission Directive 95/11/EC, Council Directive 96/51/EC.

[10] Council Regulation N $N^{\circ} 2377 / 90$ of 16 June 1990 laying down a Community procedure for the establishment of maximum residue limits of veterinary medicinal products in foodstuffs of animal origin, Official Journal L224, 18/8/1990, pp. 138144.

[11] Council Regulation $\mathrm{N}^{\circ} 2821 / 98$ of 17 December 1998 amending, as regards withdrawal of the authorisation of certain antibiotics, Directive 70/524/EEC concerning additives in feeding stuffs, Official Journal L351, 29/12/1998, pp. 4-8.

[12] Council Resolution of 8 June 1999 on antibiotic resistance 'A strategy against the microbial threat', Official Journal C 195, 13/07/1999, pp. 1-3.

[13] Decision $N^{\circ} 2119 / 98 / E C$ of the European parlament and of the council of 24 September 1998 setting up a network for the epidemiological surveillance and control of communicable diseases in the Community.

[14] EMEA: European Agency for Evaluation of Medicinal Products, Antibiotic resistance in the European Union associated with therapeutic use of veterinary medicines, Report and qualitative risk assessment by the committee for veterinary medicinal products, 1999, EMEA/CVMP/342/99.

[15] Ericsson H.M., Sherris J.C. Antibiotic sensitivity testing. Report of an international collaborative study, Acta Pathol. Microbiol. Scand. B Suppl. 217 (1971) 1-90.

[16] European Commission (1995) The Rules Governing Medicinal Products in the European Union. Volume VII - Guidelines for the testing of Veterinary Medicinal Products. December 1994, Office for Official Publications of the European Communities, Luxembourg.

[17] European Commission (1999) Opinion of the Scientific Steering Committee on Antimicrobial Resistance, Directorate-General XXIV, Consumer Policy and Consumer Health Protection Directorate B - Scientific Health Opinions Unit B3Management of scientific committees II, 1999. 
Can be downloaded on http://europa.eu.int/ comm/food/fs/sc/ssc/out50_en.html.

[18] FDA, Center for Veterinary Medicine, An approach for establishing thresholds in association with the use of antimicrobial drugs in Food Producing animals (2000), On http://www.fda.gov/ cvm/antimicrobial/antimicrobial.html.

[19] FDA, Enrofloxacin for poultry: Opportunity for hearing, Federal register 65 (2000) 64954-64965.

[20] Giraud E., Brisabois A., Martel J.-L., ChaslusDancla E., Comparative studies of mutations in animals isolates and experimental in-vitro and in-vivo mutants of Salmonella spp. suggest a counterselection of highly fluoroquinolone resistant strains in the field, Antimicrob. Agents Chemother. 43 (1999) 2131-2137.

[21] Gnanou J.C., Sanders P., Antibiotic resistance in bacteria of animal origin: methods in use to monitor resistance in EU countries, Int. J. Antimicrob. Agents 15 (2000) 311-322.

[22] Martel, J.-L., Tardy F., Brisabois A., Lailler R., Coudert M., Chaslus-Dancla E., The French antibiotic resistance monotoring programs, Int. J. Antimicrob. Agents 14 (2000) 275-283.

[23] Monnet D.L., Toward multinational antimicrobial resistance surveillance systems in Europe, Int. J. Antimicrob. Agents 15 (2000) 91-101.

[24] NCCLS, Performance Standards for Antimicrobial Disk and Dilution susceptibility tests for bacteria isolated from animals; approved standard, NCCLS document M31-A, vol. 17, $\mathrm{n}^{\circ}$ 11, pp. 160. NCCLS, Wayne, PA, USA, 1999.
[25] Neu H.C., The crisis of antibiotic resistance, Science 257 (1992) 1064-1073.

[26] Swann M., Report of the Joint Committee on the Use of Antibiotics in Animal Husbandry and Veterinary Medecine, London: Her Majesty's Stationary Office, London, UK, 1969.

[27] Van den Bogaard A.E., Stobberingh E.E., Antibiotic usage in animals - Impact on bacterial resistance and public health, Drugs 58 (1999) 589607.

[28] Van den Bogaard A.E., Stobberingh E.E., Epidemiology of resistance to antibiotics. Links between animals and humans, Int. J. Antimicrob. Agents 14 (2000) 327-335.

[29] World Health Organisation, WHO Technical Report Series $\mathrm{n}^{\circ}$ 624, Surveillance for the Prevention and Control of Health Hazards Due to Antibiotic-Resistant Drugs, 1978, 60 p.

[30] World Health Organisation, WHO global principles for the containment of antimicrobial resistance in animals intended for food. Geneva, Switzerland, 5-9 June 2000. Report of a WHO consultation, Annexe 1: Glossary, pp. 9-11.

[31] Wierup M., Preventive methods replace antibiotic growth promoters: ten years experience from Sweden, APUA Newsl. 14 (1998) 1-4.

[32] Wray C., Gnanou J.C., Antibiotic resistance monitoring in bacteria of animal origin: analysis of national monitoring programmes, Int. J. Antimicrob. Agents 14 (2000) 291-294. 

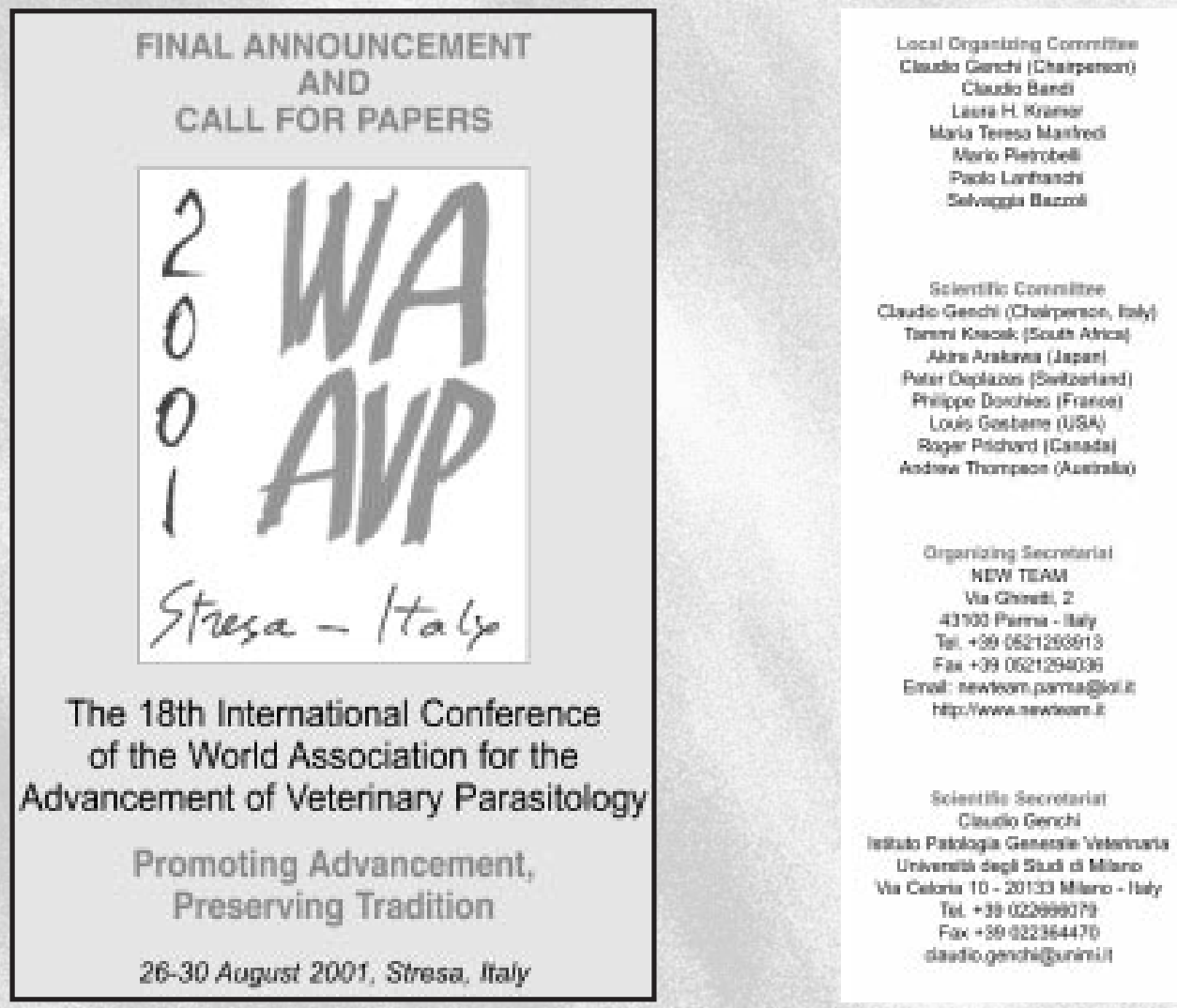

\section{INVITATION}

Dear Colleagues,

The World Association for the Advancement of Veterinary Parasitology is pleased to invite participants to the 18th International Conference which will be held in Stresa, Italy from the 26th to the 30th of August, 2001. Veterinary parasitology continues to be a rapidly growing speciality in veterinary medicine and the WAAVP conference, held every two years, represents the largest international meeting of the discipline. There have been recent and very significant increases in our understanding of host-parasite relationships, mechanisms of drug resistance, and the use of molecular biology in phylogenetic studies, epidemiology and diagnosis. The problem of "emerging" parasitic diseases in previously unaffected areas represents a challenge to both researchers and clinicians, as does the problem of parasite control in both developed and developing countries. Furthermore, the increase in animal movement and the opening of borders in some countries such as the UK has dramatically changed the risk of spreading parasitic infections and zoonotic diseases. The theme of the conference, "Promoting advancement, preserving tradition", hopes to embrace the long-standing tradition of veterinary parasitology with these and many other recent advances in the field. We invite our global colleagues to submit abstracts for the numerous oral communication and poster sessions, that will guarantee the continuous exchange of ideas between all with an interest in veterinary parasites. Finally, it will also be a good opportunity to meet old friends, to be all together and have a look at the beautiful scenery of Lake Maggiore. 